\title{
IMPLEMENTATION STAGE FOR CIRCULAR ECONOMY IN THE DANISH BUILDING AND CONSTRUCTION SECTOR
}

\author{
Lisbeth M. Ottosen ${ }^{1, \star}$, Lotte B. Jensen ${ }^{1}$, Thomas F. Astrup ${ }^{2}$, Tim C. McAloone ${ }^{3}$, Morten \\ Ryberg ${ }^{4}$, Christian Thuesen ${ }^{4}$, Søren Lütken ${ }^{4}$, Solbritt Christiansen ${ }^{5}$, Anne J. Dam ${ }^{6}$ and \\ Mads H. Odgaard ${ }^{7}$ \\ ${ }^{1}$ Department of Civil Engineering, Technical University of Denmark, Building 118, Lyngby 2800, Denmark \\ 2 Department of Environmental Engineering, Technical University of Denmark, Building 115, 2800 Lyngby, Denmark \\ ${ }^{3}$ Department of Mechanical Engineering, Technical University of Denmark, Building 404, 2800 Lyngby, Denmark \\ ${ }^{4}$ Department of Technology, Management and Economics, Technical University of Denmark, Building 424, 2800 Lyngby, Denmark \\ ${ }^{5}$ Department of Engineering Technology, Technical University of Denmark, Lautrupvang 15, 2750 Ballerup, Denmark \\ ${ }^{6}$ Department of Chemical Technology, Technical University of Denmark, Building 229, 2800 Lyngby, Denmark \\ ${ }^{7}$ Office for Research, Advice and Innovation, Technical University of Denmark, Building 101, 2800 Lyngby, Denmark
}

Article Info:

Received:

2 March 2021

Revised:

7 June 2021

Accepted:

14 June 2021

Available online:

11 September 2021

Keywords:

Circular economy

Construction and building sector

Scaling of solutions

\section{ABSTRACT}

The building and construction sector is selected by the European Commission as a key product value chain in the transition towards circular economy (CE) due to the major resource consumption, waste generation and $\mathrm{GHG}$ emissions from this sector. This paper reports the result from qualitative and semi-structured interviews with 30 Danish stakeholders from the sector on the current stage of implementation of CE and the research/innovation needs to scale circular construction from niche to the new normal. The interviews showed a large variety in the stakeholder's stage of transition from hardly knowing the term to having CE as a major driver in their business. Some meant that scaling of CE is close to impossible and that material reuse will never develop to more than a niche, whereas others already offer full-scale circular solutions to clients. The interviews pointed at a need for a common definition and terminology for $\mathrm{CE}$, methods for documenting the gains from the circular solutions (economic and environmental), methods for technical documentation of the quality of reused materials, processes which enables scaling, methods to implement CE in various systems such as digitalization and building passports, new value chains and framework conditions in support of circularity. Regardless these needs, few demonstration projects of major importance to gain general knowledge have been finalized or are planned in Denmark. These demonstrations have different approaches: using todays waste from different industries as construction materials; reusing construction materials (the basic building, elements or processed materials); and designing new buildings for disassembly to enable future reuse.

\section{INTRODUCTION}

The World's population in 2020 stands at 7.8 billion (Worldometer, 2021) people and it is projected to increase to 8.5 billion in 2030 (United Nations, 2015). With rising income and living standards, global consumption of resources such as minerals, metals and food crops increases, generating pressures on natural resources and the environment (OECD 2012). The situation is alarming and politicians at all levels point at circular economy (CE) as the only viable solution. At European level, "The circular economy package" adopted by the Commission (European Commission, 2015), created an important momentum to support the transition towards $\mathrm{CE}$, and the recent "Circular
Economy Action Plan for a Cleaner and More Competitive Europe" (European Commission, 2020)" continues and strengthen the strategy. The CE is a concept of reducing the ecological footprint by finding new concepts of the flow of matter in manufacturing processes, assuming its closed loop. The transition towards a sustainable CE model is by many seen as a solution to keep the consumption of the Earth's resources within planetary boundaries.

Building and construction is pointed out as a key product value chain in the transition towards CE in the EU (European Commission, 2015, 2020) (Hertwich, 2021). The sector requires vast amounts of resources - it accounts for about $50 \%$ of all extracted material. At the same time, the 
sector is responsible for over $35 \%$ of the EU's total waste generation. Greenhouse gas emissions (GHG) from material extraction, manufacturing of construction products, construction and renovation of buildings are estimated at $11 \%$ of total national GHG emissions (UNEP 2019). Greater material efficiency could save about $80 \%$ of those emissions according to (European Commission, 2020). The major importance of the construction and building sector for the consumption of natural resources, the GHG emissions and waste generation are strong incitements for transforming the sector towards a CE.

At company level, moving towards CE (and other sustainability-driven business models) requires a fundamental change that runs through its entire organization and it also involves its stakeholders (Ritzén \& Sandström, 2017). CE in the building sector may be considered at different stages: (1) parts that can be reused as a whole without any extra processing, (2) reused parts of the construction that need to be remanufactured, and (3) parts that require a process of recycling, e.g. after a demolition of buildings, building materials are shredded and reprocessed into new elements (Gorecki, 2018).

The major interest and awareness within research in transforming the construction and building sector to a $\mathrm{CE}$ can be seen from the large number of comprehensive literature surveys on the topic, e.g. (Benachio et al. 2020), (López Ruiz et al. 2020), and (Mhatre et al 2021). Mhatre et al. (2021) describes how the number of research papers within $\mathrm{CE}$ in the built environment have been increasing. Since the first research article on this topic was published in 2007, there has been an incremental rise in the number of publications and especially after 2016 (there were 105 papes in the first half of 2020). Thus, the research community around the topic is growing. To establish a vision it is important to both understand the current situation - e.g. what is already being done towards $C E$, or what capabilities provide a basis for this, as well as to identify what opportunities are present and desirable (Blosma et al 2019). In the acknowledgement of this, the work reported in this paper sets off in interviewing the construction and building sector itself, and on the description of the transformation seen from the inside towards the larger perspectives. Major findings from a sector development project "Circular construction and building sector" are reported - a project, which takes off in the Danish construction sector's own understanding of challenges, barriers and opportunities in the transition towards CE. A major aim is to identify the challenges faced by the sector itself and to evaluate the research and innovation that can aid meeting these challenges.

\section{METHOD}

At the Technical University of Denmark (DTU), the board of directors decided (2019) to conduct the sector development project "Circular construction and building sector" presented in this paper. The DTU procedure for such projects is to frame and focus the topic on collaboration with the major relevant Danish associations, which are also project owners. A local, interdisciplinary university team is set. This team is responsible for the execution of the project.
The core of the project is a series of interviews with different stakeholders. The university team compiles the findings from the interviews. The outcome of the interviews is presented at a workshop where the associations, the interviewed persons and the university team meet and discuss the compiled result. The common conclusions are drawn on basis of the inputs from the workshop. The outcome is published in a report (in Danish), which for the present sector development project is planned for the spring 2021.

The Danish associations in the present project were the Danish Association of Architectural Firms (www.danskeark. dk), the Danish Construction Association (www.danskbyggeri.dk), the Federation of Danish Building Industries (www. danskindustri.dk/brancher/di-byg), the Danish Association of Consulting Engineers (www. frinet.dk) and SEGES (www. seges.dk). The associations suggested different, specific stakeholders for interviews based on their relative importance in the industry and maturity on circular practices. Altogether 30 interviews were conducted among Danish construction clients, architectural companies, consulting engineering companies, construction material producers, contracting companies, public institutions (waste management and recycling, authorities e.g. municipalities responsible of building facility management) and trade associations. Few selected public institutions and organizations in the Netherlands and Belgium were interviewed as well to set the Danish findings in perspective with other countries driving the circularity agenda. The stakeholders were interviewed one by one by 1-4 members of the research team. The interviews were qualitative and semi-structured (Brinkmann \& Kvale 2018) each lasting 1-2 hours and based on a common question guide with 17 questions organized in 2 sections and 4 themes.

The first section of questions, three in number, were clarifying questions about the company/institution (value creation from products/services, customers/users and national/international market).

The second section of questions were focused around $\mathrm{CE}$ and had a sequence of themes to be covered:

- Burning platform. Is there a burning platform in Denmark and internationally? What is it? Which part of the build environment constitutes the major needs/possibilities?

- Tendencies related to CE. Questions on which tendencies were seen within major topics of CE from the key words: recirculation, building design, building passes, economy and environmental assessments, value chains, digitalization, city and regional perspectives, scaling of solutions, standardization, incitement, procurement rules, risk and responsibility, and the role of technology.

- Transformation towards CE: This group of questions had the key words: visions, necessary leadership, requests to society, challenges and possibilities, export options

- Research and innovation needs: The major challenges and also specifically the major research needs. The companies were also asked about their experiences on collaboration with researchers. 
Due to the semi structured nature of the interviews, there was openness to change the sequence and questioning form. The interviews had periods with dialog on the answers and stories told by the interviewees until the themes from the interview guide were covered. After each interview, the core findings were documented and summarized. The analysis was undertaken by the research team enabling triangulation of data and theoretical perspectives given the interdisciplinary organization of the team. The findings were subsequently validated through an online workshop with participation of the interviewed persons, the five associations and the university researchers. The results from the interviews were outlined and discussed.

The university departments involved in the project were DTU Civil Engineering, DTU Environment, DTU Mechanical Engineering, DTU Management, DTU Engineering Technology, and DTU Chemical Engineering. The project is led by the DTU Office for Research, Advice and Innovation. The core of the interdisciplinary university team were the authors of this paper.

\section{RESULTS}

\subsection{General status on CE in the Danish construction and building sector}

Through the 30 interviews, it was evident that there is a lack of common understanding of the term CE in the Danish construction and building sector. This even though the EU has pointed at the sector as a key value chain in the transition. The lack is in line with what has been reported in literature on a broader term, e.g. (Kirchherr et al 2017) states from a review of more than hundred papers and reports that CE means different things to different people. A basic explanation for a CE economy is 'where the value of products, materials and resources is maintained in the economy for as long as possible, and the generation of waste minimised' (European Commission, 2015). In (Kirchherr et al 2017) CE is defined as "an economic system that replaces the 'end-of-life' concept with reducing, alternatively reusing, recycling and recovering materials in production/distribution and consumption processes". Thus the core of CE is based on material and resource use. However, in the interviews, the companies often equaled CE to GHG emissions or UNs 17 SDGs in general terms.

\subsection{The sector about the burning platform}

The burning platform identified by the companies was related to the major trends threatening the state of the globe, mainly GHG emissions but also increasing population and following resource scarcity and waste generation was often mentioned. However, these megatrends were not translated into a direct burning platform for the companies themselves necessitating their transition towards $C E$, i.e. the companies did not mention at all that they felt a push towards taking any action themselves. For the interviewed companies already active in implementing CE (partly or a more thorough reorganization) the basis for doing so was established on an idealistic standpoint or because adapting CE was seen as a way to specialize and thus as a business opportunity.
When describing challenges close to the stakeholders, the loss of common craftsmanship during the past 50 years of industrialization of the construction sector was mentioned from a few of them as a coming need to cope with in relation to a transition to $\mathrm{CE}$. From some of the large enginieering companies it was also mentioned that attracting young people depends increasingly on having a green profile and that the change in mindset will grow from the young generation. Throughout the interviews there was no specific part of the built environment which was pointed out to constitute the major needs/possibilities in relation to $\mathrm{CE}$, however it was mentioned, that the transformation must include both renovation and new buildings.

\subsection{The sector on the transformation towards CE}

The possibility for scaling CE from being a niche to common practice was often brought up during the interviews. Some believed that scaling of CE in construction is close to impossible in practice and thus that material reuse will never develop to more than a niche, whereas others believed that it was definitely possible to scale the construction with reused materials and that it will be the new normal. Many pointed and responsibility when reusing or using recycled materials was pointed out as a major obstacle. As materials and components directly reused are not certified, the accompanied risk needs to be assumed by the construction client or the consulting engineering company. Standardization was suggested as the way forward. Many of the interviewed persons expressed that as long as the circular solutions are more expensive than today's linear solutions, a general transformation to CE will not happen.

At the final common workshop, which gathered the interviewed persons, strong emphasis was laid on a national road map as a tool to move the sector forward. A vision of transforming Denmark to a living lab for CE in the construction industry was brought forward and supported by many of the participants.

\subsection{The sector on major challenges and research needs}

A major objective of the present sector development project was to identify the technological challenges and research/innovation needs that sector is facing in relation to a transition to $C E$, and hereby to foster concrete ideas for collaboration between universities and companies. Those of the companies, who were experienced in working with university researchers pointed at common MSc and $\mathrm{PhD}$ students as a good way of collaboration. The conducted interviews pointed at the need for:

- Common definition and terminology for circular economy;

- Methods for documenting the value (economic and environmental) of circular materials and building processes;

- Technical knowledge on minimizing the risk when choosing to reuse or recycle construction materials;

- Implementation of circular solutions in digital tools (such as BIM) as well as in material- and building passports; 
- Circular processes which can enable scaling;

- Methods to ensure full circularity of materials and building elements;

- Systems for connecting value chains in the building and construction industry with other adjacent value chains.

- Framework and conditions for tendering, services, building regulations etc. for support to circularity

\section{DISCUSSION}

The fast-growing awareness of CE to be the strategy to follow to simultaneously combat resource depletion and lower the GHG emissions as well as waste generation, and the major role of the building and construction sector both as part of the problem and thus also a part of the solution, necessitate revisiting the current practice in the sector, which is built on a linear use of materials. The interviews in the current investigation showed that the Danish construction and building sector was aware of the sectors responsibility in relation to a more sustainable society. All the interviewed persons showed interest (and most also enthusiasm) in the developments combating the global threats, but many expressed reservations whether the sector in general and not at least the building owners will value environmental concerns before economy. This was seen as a major obstacle. Lopéz Ruiz et al. (2020) reviewed the transformation of the construction and demolition sector to a $C E$, and concluded that research in this sector has mainly focused on aspects regarding reuse and recycling from an environmental performance perspective and that the integration of economic criteria is still limited. Thus the attention to the limited focus on economic issues in the transition, raised from the interviewed persons, is an issue beyond the Danish sector.

The CE agenda does not apply only to closing the loop and use "waste as resource". The transition to a CE can be achieved through an agenda integrating three strategies a) closing resource loops via recycling along the material value chain $b$ ) narrowing loops i.e. increasing resource efficiency by using less material input for production and producing less waste for final disposal, and c) slowing loops i.e. lengthening the use phase via development of long-life goods and materials and product-life extension measures (Baldassarre et al 2019). These three strategies are in line with the waste hierarchy, i.e. reduce, reuse, recycle and recover (European Parliament and the Council, 2008). Academia as well as practitioners use the waste hierarchy as basis for development of a CE framework (Prieto-Sandoval et al. 2018). Those of the interviewed persons, who did not automatically equate $\mathrm{CE}$ to lowering $\mathrm{CO} 2$ emissions or SDGs, were focused around closing the loops. Neither of the interviewed included narrowing or slowing loops in their reflections.

One of the needs pointed out by many of the interviewed, was the need for a common definition and understanding of $\mathrm{CE}$ as well as standardization. Recently, the Danish Standards was appointed (December 2020) by CEN to lead and run a new European technical committee on $\mathrm{CE}$ related to the building sector - CEN/TC 350/SC1 circular economy in the construction sector. As a first step, a framework for the CE terminology will be developed so that there is common international agreement on what is meant by CE in the sector. Thus work is in progress on developing a common international terminology, and this must be considered very important step in order for the sector to unite in the transition, which is already a political strategy nationally and in the EU. Pointing at standardization as major important, the Danish sector was in line with the general viewpoint, as e.g. Benachio et al (2020) reported from a systematic literature review that the consensus is that there is good level of awareness of the need of change from the linear to the $\mathrm{CE}$ in the construction industry, however practitioners argue about the lack standardized methods and practices to help them implement in their construction projects.

\section{CONCLUSIONS}

The state of the transformation to CE of the Danish construction and building sector was the focus in the current project initiated by the Technical University of Denmark. Five trade associations were involved in framing the project, and 30 interviews were carried out with different stakeholders in the sector. The interviews showed lack of common definition for CE in the sector, that the companies were at different stages in the transition (some had no actual plans whereas others had CE as the main driver for business), and that clarification of risk/responsibility issues is necessary at many levels in order to implement CE in the sector. This point to a second conclusion regarding the sectors own viewpoint of having incomplete or insufficient measures to determine pathways for the changes required by the sector. Important demonstration projects have been build or are planned, however, to scale and to common practice the interviews pointed at needs for: methods for documenting the economic and environmental gains, technical methods for documenting the quality of reused materials, processes which enables scaling and development of new value chains. The interviews also indicated that it may be necessary to update the framework conditions so they support the transformation to $\mathrm{CE}$, and some pointed at a need for an external push to move the sector towards a CE.

\section{AKNOWLED GEMENTS}

The board of directors at DTU for choosing "Circular construction and building" as theme. Danish Association of Architectural Firms, the Danish Construction Association, the Federation of Danish Building Industries, the Danish Association of Consulting Engineers and SEGES for the collaboration on framing the project. We are greatful to all interviewed persons for open and inspiring sharing of knowledge and viewpoints.

\section{REFERENCES}

Baldassarre, B., Schepers, M., Bocken, N., Cuppen, Korevaar, G., Calabretta, G. (2019) Industrial Symbiosis: towards a design process for eco-industrial clusters by integrating Circular Economy and Industrial Ecology perspectives, J. Clean. Prod. 216, 446-460

Benachio, G.L.F., Freitas, M.C.D., Tavares, S.F. (2020) Circular economy in the construction industry: A systematic literature review. Journal of Cleaner Production 260, 121046 
Blomsma, F., Pieroni, M., Kravchenko, M., Pigosso, D.C.A., Hildenbrand, J., Kristinsdottir, A.R., Kristoffersen, E. Shahbazi, S., Nielsen, K.D. Jönbrink, A.-K., Li, J., Wiik, C., McAloone, T.C. (2019) Developing a circular strategies framework for manufacturing companies to support circular economy-oriented innovation. J. Clean. Prod. 241, 118271

European Commission (2015). Closing the Loop - an EU Action Plan for the Circular Economy. Communication from the Commission to the European Parliament, the Council, the European Economic and Social Committee and the Committee of the Regions. COM(2015) 614 final.

European Commission (2020). Circular Economy Action Plan for a Cleaner and More Competitive Europe. Communication from the Commission to the European Parliament, the Council, the European Economic and Social Committee and the Committee of the Regions.

European Parliament and the Council (2008) Directive 2008/98/EC of the European Parliament and of the Council of 19 november 2008 on waste and repealing certain directives. Off. J. Eur. Communities, L312/3 (2008), pp. 3-30.

Gorecki, J. (2019) Circular Economy Maturity in Construction Companies. Conference Series: Materials Science and Engineering 471(11), 112090

Hertwich, E. G. (2021). Increased carbon footprint of materials production driven by rise in investments. Nature Geoscience, 1-5.

Kirchherr, J.; Reike, D.; Hekkert, M. Conceptualizing the circular economy: An analysis of 114 definitions. Resources, Conservation \& Recycling 127 (2017) 221-232

Brinkmann, S., \& Kvale, S. (2018). Doing interviews (Second ed.). SAGE Publications Ltd

Lejrbo (2020) https://www.lejerbo.dk/om-lejerbo/byggeri/circle-house (In Danish, visited Sept. 2020)
Lendager (2013) https://lendager.com/en/architecture/upcycle-house-en/ (Visited Sept, 2020)

Lendager (2018) https://lendager.com/arkitektur/upcycle-studios/ (In Danish, visited Sept, 2020)

López Ruiz, L.A.L., Ramón, X.R., Domingo, S.G. (2020) The circular economy in the construction and demolition waste sector - A review and an integrative model approach. Journal of Cleaner Production 248, pp. 119238

Mhatre, P., Gedam, V., Unnikrishnan, S., Verma, S. (2021) Circular economy in built environment - Literature review and theory development. Journal of Building Engineering 35, 101995

Musicon (2020) https://musicon.dk/ (In Danish, visited Sept. 2020)

Næste Skur (2019) https://www.naeste.dk/ (In Dansih, visited February 2021)

$\operatorname{OECD}(2012)$ Sustainable materials management, making better use of resources

Prieto-Sandoval, V., Jaca, C., Ormazabal, M. (2018) Towards a consensus on the circular economy. Journal of Cleaner Production 179, 605-615

Ritzén, S., Sandström, G.Ö. (2017) Barriers to the Circular Economy integration of perspectives and domains. Procedia CIRP 64, 7- 12

United Nations, Department of Economic and Social Affairs, Population Division (2015). Population 2030: Demographic challenges and opportunities for sustainable development planning (ST/ESA/ SER.A/389)

UNEP, 2019. 2019 global status report for buildings and construction: Towards a zero-emission, efficient and resilient buildings and construction sector. Global Alliance for Buildings and Construction, International Energy Agency and the United Nations Environment Programme.

Worldometer (2021) https://www.worldometers.info/world-population/ (visited February 2021) 